\title{
Birthweight Centile Charts for South Asian Infants Born in the UK
}

\author{
Sarah E. Seaton Kamini D. Yadav David J. Field Kamlesh Khunti \\ Bradley N. Manktelow \\ Department of Health Sciences, University of Leicester, Leicester, UK
}

\section{Key Words}

Birthweight $\cdot$ Centile $\cdot$ Ethnicity

\begin{abstract}
Background: UK-born infants of South Asian ethnic origin are known to have lower birthweights than their White British counterparts. When plotted on currently used birthweight charts they can be misclassified as small for gestational age. Similarly, large for gestational age infants can be missed. This has important clinical implications in their management. Objective: To create birthweight centile charts for the UK-born South Asian infants to identify true small and large for gestational age infants. Methods: A retrospective cross-sectional analysis of infants born 1 January 2003 to 31 December 2006 was undertaken. The birthweights of the South Asian and White British infants were compared. The LMS method was used to construct centile charts for the South Asian infants. Results: 24,274 White British and 7,190 South Asian infants were included in the analysis. Overall, the South Asian males were 9-15\% lighter than the White British males and the South Asian females were 9-13\% lighter than the White British females. At term, the median birthweight for South Asian males was $329 \mathrm{~g}$ lower than that for White British males and for South Asian females $295 \mathrm{~g}$ less than the White British females. Conclusion: There are significant differences in the birthweights of White British and
\end{abstract}

UK-born South Asian infants. Hence the standard birthweight centile charts which were designed using the birthweight data of White British infants appear to misclassify a proportion of South Asian infants. Use of ethnic specific birthweight charts would allow better detection of truly growth-restricted and macrosomic South Asian infants.

Copyright $\odot 2011$ S. Karger AG, Basel

\section{Background}

Birthweight has traditionally been used by neonatologists as a proxy for intrauterine fetal growth. It helps to identify babies who need additional monitoring or intervention after birth and is a predictor of a person's health over their life course. Small for gestational age infants (SGA: birthweight <10th centile) form a heterogeneous group comprising normally grown constitutionally small infants and those who have failed to reach their full genetic growth potential because of maternal, placental or genetic problems. They are at increased risk of morbidity and mortality throughout infancy $[1,2]$ and at risk of chronic health problems in adulthood [3-5], and hence it is important to identify SGA infants accurately.

Similarly, the large for gestational age (LGA: birthweight $>90$ th centile) group comprises normal infants who are constitutionally large and those who are large

\section{KARGER \\ Fax +4161306 1234 E-Mail karger@karger.ch} www.karger.com

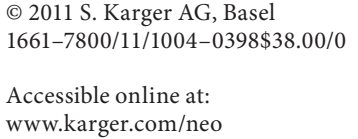

Sarah E. Seaton, BSc (Hons)

Department of Health Sciences, University of Leicester

22-28 Princess Road West

Leicester LE1 6TP (UK)

Tel. +44 116252 5407, E-Mail sarah.seaton@le.ac.uk 
due to a pathological antenatal growth pattern (for example as a complication of maternal diabetes). Pathologically macrosomic infants are also at increased risk of short- and long-term health problems $[6,7]$.

It is well recognised that there is wide variation in the birthweight of infants depending on ethnicity [8-12]. Based on previous estimates infants from the South Asian ethnic group have a different distribution of birthweights and are on average 200-300 g less than their White British counterparts [13]. The standard population-based birthweight charts (UK 1990) currently used in the UK were designed in 1990 using the birthweight data of only White British infants [14]. These birthweight charts are used to determine which babies are 'at risk' as they fall either into the SGA or LGA category. Inevitably, using this approach South Asian babies are more often classified as SGA and less likely to seen as LGA.

The University Hospitals of Leicester NHS Trust (UHL) serves a population of diverse ethnicities. The two main ethnic groups of mothers who deliver at UHL are White British (65.4\%) and South Asians (19.4\%). At UHL, the UK 1990 birthweights charts are used to plot all infants irrespective of their ethnic origin and we face these issues of birthweight misclassification on a daily basis [14, 15]. Using the birthweight data of South Asian infants born in Leicester, we produced birthweight centile charts for this population. We also wished to use our charts to estimate the scale of the misclassification of South Asian infants by using the current birthweight (UK 1990) charts.

\section{Methods}

Data were obtained from the obstetric database maintained at the University Hospitals of Leicester for all intrapartum stillbirths and live births from 1 January 2003 to 31 December 2006. Infants were included if their mothers were of White British (British or Irish) or South Asian (Indian, Pakistani, Bangladeshi and Sri Lankan) ethnic origin. Ethnic origin recorded in the database was self-reported and as recorded in the maternal notes at the time of booking. There was no information regarding paternal ethnicity or interracial relationships. The White British and South Asian infants were included in this paper if they were singleton, born between 32 and 42 weeks of gestational age (rounded to the nearest week) and alive at the onset of labour. Gestational age was determined by using the expected date of delivery estimated by firsttrimester ultrasound. Infants were excluded if gender or birthweight was unknown or the recorded birthweight was implausible. An implausible birthweight was defined as any birthweight for a given gestational age which was more than 3 standard deviations from the median or deemed to be clinically implausible.

Birthweight Centile Charts for South Asian Infants Born in the UK
The LMS method was used to estimate the birthweight centiles [16]. The L (Box-Cox power), M (median) and S (coefficient of variation) parameters were estimated using the GAMLSS package [17] in $\mathrm{R}$ version 2.9 [18] as recommended by the World Health Organisation (WHO) [19]. This method uses smoothed values of $\mathrm{L}, \mathrm{M}$ and $\mathrm{S}$ to transform the observed distribution of birthweights to a standard normal distribution. This then allows the calculation of centiles by using the appropriate SD score.

The small number of preterm babies of South Asian ethnic origin could have resulted in unreliable estimates of the parameters for these babies. To overcome this problem, it was recognised that the functional form of the parameters were likely to be similar for both South Asian and White British infants. Including the much larger cohort of White British infants and jointly modelling the two populations in a single model allowed more reliable estimates to be obtained for the South Asian infants. Estimated values for the parameters $\mathrm{L}, \mathrm{M}$ and $\mathrm{S}$ were obtained based on gestational age, birthweight, gender and ethnic group. Two- and three-way interactions were considered between all variables and included if they reduced the value of the Akaike Information Criterion (AIC) substantially.

The estimated LMS scores (table 1) were then converted into centiles using the formula:

$$
y=M[1+S L \cdot \Phi(p)]^{1 / L},
$$

where $\Phi(p)$ is the critical value of the normal distribution for a given centile.

The final centile charts were created using Stata version 11 [20]. All other analysis was completed in R version 2.9 [18].

Ethical approval to proceed without individual consent was given on the basis that this was a retrospective anonymised clinical dataset.

\section{Results}

A total of 38,049 singleton infants were born at the University Hospitals of Leicester from January 2003 to December 2006: 24,881 (65.4\%) White British, 7,369 (19.4\%) South Asian, 4,008 (10.5\%) other, and 1,791 (4.7\%) had no ethnicity specified. Of these, 31,621 met the inclusion criteria and 157 were excluded: unknown gender $(\mathrm{n}=1)$, unknown birthweight $(\mathrm{n}=1)$, and implausible birthweight $(\mathrm{n}=155)$. Of the 31,464 infants included in the analysis, 24,274 were White British (51.9\% male) and 7,190 were South Asian (50.9\% male). The South Asians comprised a group of Indian (84.0\%), Bangladeshi (7.0\%), Pakistani (8.8\%), and Sri Lankan (0.2\%) origin. The number of infants born in each gestational week for the two ethnic groups is given in table 2 .

The gestation-specific smoothed median birthweights for South Asian males were 9-15\% lighter than those for the White British males (table 3). Similarly, the smoothed median birthweights for the South Asian females were 9-13\% lighter than the White British females. If the cur- 
Table 1. Estimated values for $L, M$ and $S$ parameters by ethnic group and gestational age

\begin{tabular}{|c|c|c|c|c|c|c|}
\hline \multirow{2}{*}{$\begin{array}{l}\text { Gestational } \\
\text { age, weeks }\end{array}$} & \multicolumn{3}{|c|}{ Male } & \multicolumn{3}{|c|}{ Female } \\
\hline & $\mathrm{L}$ & M & $\mathrm{S}$ & $\mathrm{L}$ & M & $\mathrm{S}$ \\
\hline \multicolumn{7}{|l|}{ South Asian } \\
\hline 32 & 1.03 & 1,485 & 0.21 & 0.72 & 1,404 & 0.21 \\
\hline 33 & 0.95 & 1,729 & 0.20 & 0.64 & 1,643 & 0.20 \\
\hline 34 & 0.86 & 1,973 & 0.19 & 0.55 & 1,882 & 0.19 \\
\hline 35 & 0.78 & 2,204 & 0.18 & 0.47 & 2,108 & 0.18 \\
\hline 36 & 0.70 & 2,421 & 0.17 & 0.39 & 2,321 & 0.17 \\
\hline 37 & 0.61 & 2,636 & 0.16 & 0.30 & 2,531 & 0.16 \\
\hline 38 & 0.53 & 2,866 & 0.15 & 0.22 & 2,755 & 0.15 \\
\hline 39 & 0.45 & 3,069 & 0.14 & 0.14 & 2,954 & 0.14 \\
\hline 40 & 0.36 & 3,206 & 0.13 & 0.05 & 3,086 & 0.13 \\
\hline 41 & 0.28 & 3,339 & 0.12 & -0.03 & 3,214 & 0.13 \\
\hline 42 & 0.20 & 3,441 & 0.12 & -0.12 & 3,312 & 0.12 \\
\hline \multicolumn{7}{|l|}{ White British } \\
\hline 32 & 1.55 & 1,745 & 0.20 & 1.24 & 1,610 & 0.21 \\
\hline 33 & 1.46 & 1,998 & 0.19 & 1.15 & 1,860 & 0.20 \\
\hline 34 & 1.38 & 2,251 & 0.18 & 1.07 & 2,111 & 0.19 \\
\hline 35 & 1.30 & 2,490 & 0.17 & 0.99 & 2,348 & 0.18 \\
\hline 36 & 1.21 & 2,716 & 0.16 & 0.90 & 2,571 & 0.17 \\
\hline 37 & 1.13 & 2,939 & 0.15 & 0.82 & 2,792 & 0.16 \\
\hline 38 & 1.05 & 3,177 & 0.14 & 0.74 & 3,028 & 0.15 \\
\hline 39 & 0.96 & 3,390 & 0.13 & 0.65 & 3,238 & 0.13 \\
\hline 40 & 0.89 & 3,535 & 0.12 & 0.57 & 3,381 & 0.13 \\
\hline 41 & 0.80 & 3,676 & 0.12 & 0.48 & 3,520 & 0.12 \\
\hline 42 & 0.71 & 3,787 & 0.12 & 0.40 & 3,628 & 0.12 \\
\hline
\end{tabular}

rently used UK 1990 centile $[14,15]$ charts were used, $13.5 \%$ of South Asian infants born at 32-40 weeks' gestational age $(\mathrm{n}=740)$ would have been identified incorrectly as SGA. Similarly, $6.9 \%$ of LGA South Asian infants $(\mathrm{n}=379)$ born at 32-40 weeks' gestational age would have not been identified by the UK 1990 charts.

Successful management of diabetic pregnancy is often judged by the avoidance of macrosomia in the baby. To assess the impact of using our centile charts on this particular clinical measure, we performed a sub-analysis on 150 South Asian women confirmed as having gestational diabetes mellitus and who delivered between 32 and 40 weeks' gestational age. In these infants our charts identified 27 infants as LGA, whilst current charts identified 18 infants. Similarly, our charts identified only 5 infants as SGA, whilst current charts identified 18 infants.

The L, M and S parameters were estimated (table 1) which allows the estimation of any specified centile using the algorithm given earlier. Estimated centile charts for South Asian males (fig. 1) and South Asian females (fig. 2)
Table 2. Number of White British and South Asian infants by their ethnicity and gestational age

\begin{tabular}{lrrrrr}
\hline \multirow{2}{*}{$\begin{array}{l}\text { Gestational } \\
\text { age }\end{array}$} & \multicolumn{2}{l}{ White } & & \multicolumn{2}{c}{ South Asian } \\
\cline { 2 - 3 } \cline { 5 - 6 } & males & females & & males & females \\
\hline 32 & 37 & 30 & 5 & 13 \\
33 & 62 & 46 & 24 & 10 \\
34 & 83 & 64 & 32 & 16 \\
35 & 120 & 115 & & 34 & 33 \\
36 & 232 & 165 & 80 & 67 \\
37 & 504 & 420 & 199 & 171 \\
38 & 1,113 & 901 & & 479 & 427 \\
39 & 2,381 & 2,217 & & 914 & 945 \\
40 & 3,282 & 3,197 & & 1,016 & 1,002 \\
41 & 3,046 & 2,956 & & 599 & 588 \\
42 & 1,725 & 1,578 & 276 & 260 \\
\hline Total & 12,585 & 11,689 & 3,658 & 3,532 \\
\hline
\end{tabular}

Table 3. Smoothed median birthweights for the South Asian and White British males and females with differences between the weights presented

\begin{tabular}{|c|c|c|c|c|c|c|}
\hline \multirow{3}{*}{$\begin{array}{l}\text { Gesta- } \\
\text { tional } \\
\text { age } \\
\text { weeks }\end{array}$} & \multicolumn{6}{|c|}{ Median weight, $\mathrm{g}$} \\
\hline & \multicolumn{3}{|l|}{ males } & \multicolumn{3}{|c|}{ females } \\
\hline & $\begin{array}{l}\text { White } \\
\text { British }\end{array}$ & $\begin{array}{l}\text { South } \\
\text { Asian }\end{array}$ & $\begin{array}{l}\text { differ- } \\
\text { ence }\end{array}$ & $\begin{array}{l}\text { White } \\
\text { British }\end{array}$ & $\begin{array}{l}\text { South } \\
\text { Asian }\end{array}$ & $\begin{array}{l}\text { differ- } \\
\text { ence }\end{array}$ \\
\hline 32 & 1,745 & 1,485 & 260 & 1,610 & 1,404 & 206 \\
\hline 33 & 1,998 & 1,729 & 269 & 1,860 & 1,643 & 217 \\
\hline 34 & 2,251 & 1,973 & 278 & 2,111 & 1,882 & 229 \\
\hline 35 & 2,490 & 2,204 & 286 & 2,348 & 2,108 & 240 \\
\hline 36 & 2,716 & 2,421 & 295 & 2,571 & 2,321 & 250 \\
\hline 37 & 2,939 & 2,636 & 303 & 2,792 & 2,531 & 261 \\
\hline 38 & 3,177 & 2,866 & 311 & 3,028 & 2,755 & 273 \\
\hline 39 & 3,390 & 3,069 & 321 & 3,238 & 2,954 & 284 \\
\hline 40 & 3,535 & 3,206 & 329 & 3,381 & 3,086 & 295 \\
\hline 41 & 3,676 & 3,339 & 337 & 3,520 & 3,214 & 306 \\
\hline 42 & 3,787 & 3,441 & 346 & 3,628 & 3,312 & 316 \\
\hline
\end{tabular}

were constructed showing the 2nd, 9th, 25th, 50th, 75th, 91st and 98th centiles.

To assess the validity of the LMS scores for South Asian babies, the expected percentage of observed birthweights lying above each centile was compared with the observed percentage across the gestational ages included in this study (table 4). The centiles predicted well both overall and at individual weeks of gestational ages where there was sufficient data to confidently assess the performance of the charts. 


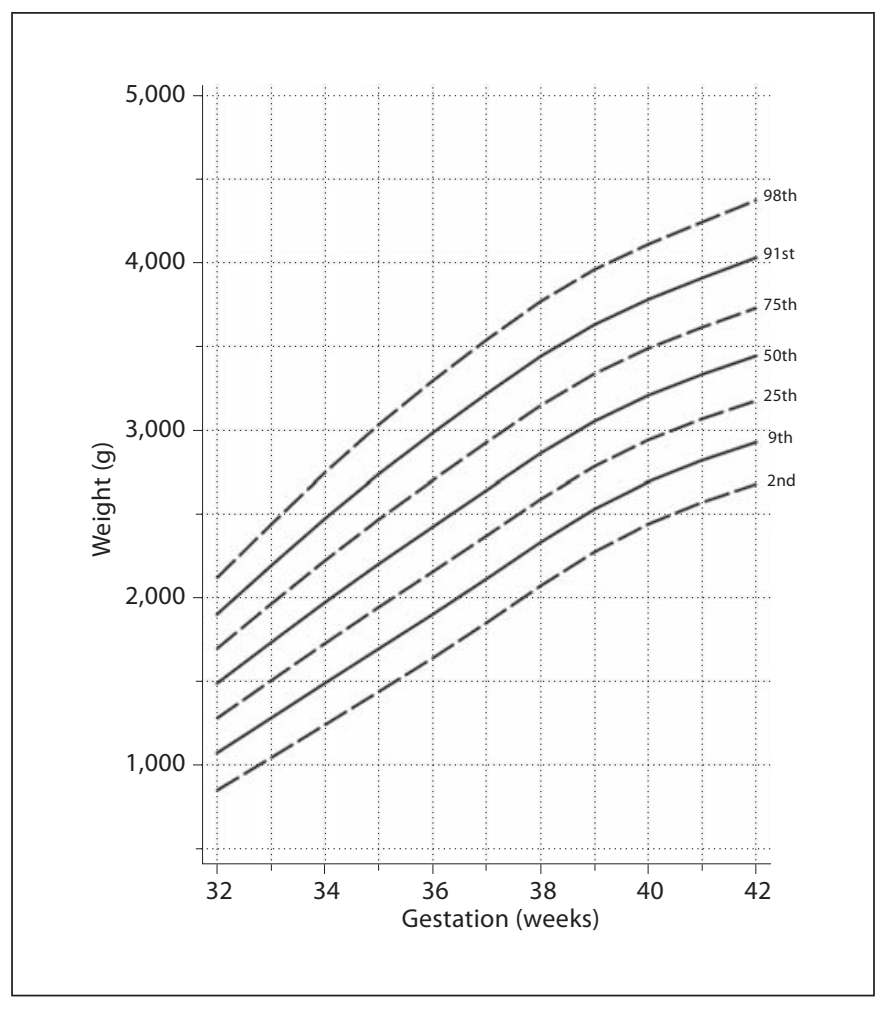

Fig. 1. 2nd, 9th, 25th, 50th, 75th, 91st and 98th centiles for South Asian males.

\section{Discussion}

In an ethnically diverse population, substantial differences exist in birthweight between ethnic groups and the likely scale of this difference in the UK has been previously suggested by Chinn et al. [13, 21].

Recently, the WHO released new infant growth charts for children from 2 weeks to 4 years of age to be used for all ethnic groups. The Royal College of Paediatrics and Child Health (RCPCH) decided to adopt these growth charts for use in the UK but to continue to use the preterm and term birthweight centile charts developed by Freeman et al. [14] in the UK 1990 study. The UK 1990 birthweight centile charts were developed by combining 5 UK birthweight surveys. These surveys had a small proportion of non-White children who were excluded from the analyses because of known differences between the ethnic groups as they would increase the variance of the centiles. At that time, ethnic minority groups comprised a small proportion of the UK population and the authors were unable to design separate centile charts for each ethnic group [15]. However, the proportion of births in the

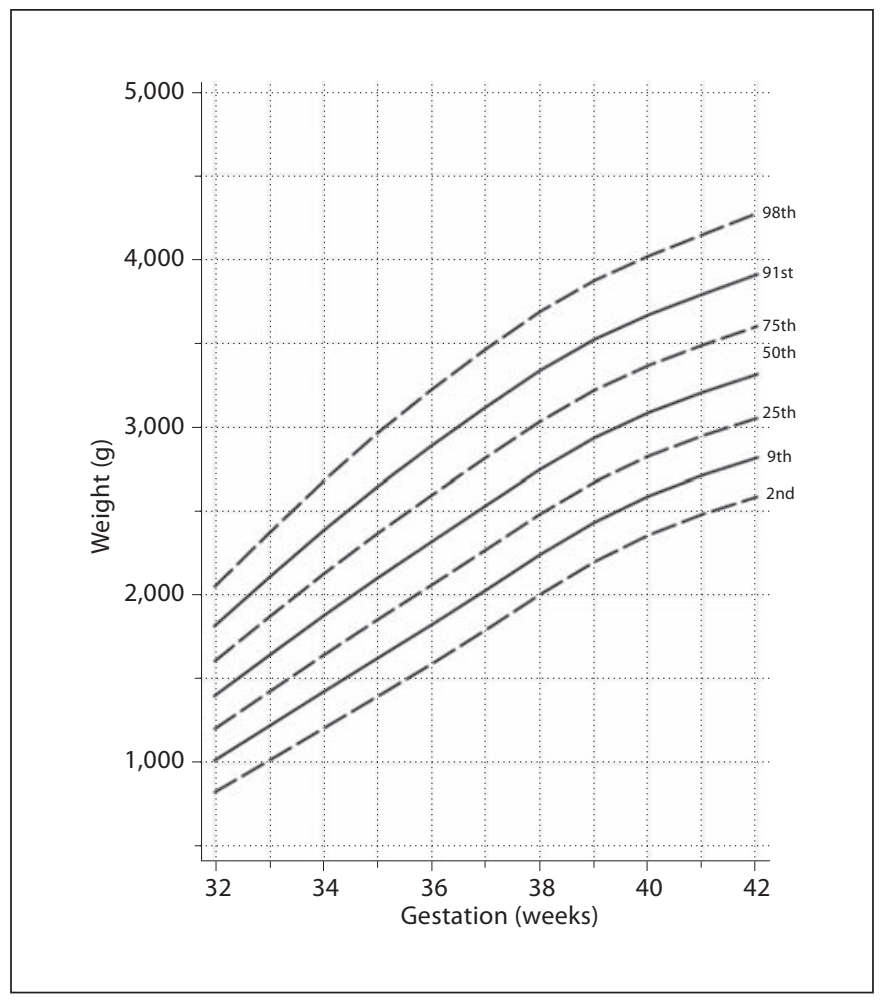

Fig. 2. 2nd, 9th, 25th, 50th, 75th, 91st and 98th centiles for South Asian females.

Table 4. Observed and expected percentage of points above each centile band across all gestational ages for South Asian males and females

\begin{tabular}{|c|c|c|c|}
\hline \multirow[t]{2}{*}{ Centiles } & \multirow{2}{*}{$\begin{array}{l}\text { Expected } \\
\text { percentage } \\
\text { above centile }\end{array}$} & \multicolumn{2}{|c|}{ Observed percentage above } \\
\hline & & $\begin{array}{l}\text { South Asian } \\
\text { males }\end{array}$ & $\begin{array}{l}\text { South Asian } \\
\text { females }\end{array}$ \\
\hline Above 2nd & 98 & 97.5 & 98.0 \\
\hline Above 9th & 91 & 90.4 & 91.9 \\
\hline Above 25th & 75 & 75.7 & 77.4 \\
\hline Above 50th & 50 & 50.1 & 49.0 \\
\hline Above 75th & 25 & 24.8 & 23.2 \\
\hline Above 91st & 8 & 9.0 & 9.0 \\
\hline Above 98th & 2 & 2.4 & 2.1 \\
\hline
\end{tabular}

UK of children of South Asian ethnic origin has increased since the development of the UK 1990 centile charts. Therefore, the data to create separate ethnic birthweight charts, which were limited in the UK 1990 study, are now more readily available. 
In the population we studied there was a difference in the birthweights of infants of the two major ethnic groups: White British and South Asian. This difference was noted across all gestational ages from preterm to term infants. Whilst the difference in centile allocation was apparent across the gestation range depending on which charts were used, the potential impact of these findings is most likely to be seen in term infants. This is both because the numbers affected are large and without a label such as 'SGA' or 'LGA' the care of these babies would not normally involve anything other than routine supervision from the mother and/or midwife. Being classified as SGA or LGA normally results in a different care pathway with greater intervention and often a longer stay in hospital.

The implications of misclassification are not only short term but they could also have potential long-term harmful health implications. The parents of the wrongly classified SGA infant would believe that their child was growth-restricted and hence be under pressure to see their child grow to a higher centile with the danger of overfeeding during infancy and childhood which increases the risk of obesity and adult cardiovascular diseases $[23,24]$. These same issues led to the introduction of new WHO growth charts as the older charts misclassified healthy breast-fed babies to lower weight centiles and this put enormous pressure on breast-feeding mothers to overfeed their babies. This skewed the growth and infant nutrition towards overfeeding and obesity.

Another example of one immediate impact of using birthweight charts specific for different ethnic groups is to aid identification of the true proportion of macrosomic babies (birthweight above the 90th centile) born to mothers with gestational diabetes mellitus (GDM). About 40\% of women with GDM [25] are not identified by the current screening methods and the prevalence of GDM is 11 times higher for South Asian women compared to White British women [26]. A South Asian mother with undetected and untreated GDM which led to the birth of a macrosomic infant needs to be identified and appropriately counselled regarding diet and lifestyle interventions. If not, she is likely to develop GDM in subsequent pregnancies or she might gradually progress to type 2 diabetes silently, developing macro- and microvascular complications. She could potentially then enter her next pregnancy as a diabetic where the risk of fetal complications is significantly higher.

We are not the first to recognise this problem of inappropriate classification of birthweight. A recent Canadian study published ethnic specific birthweight centiles for a small population of South Asian infants born in
Canada and the authors recommended that birthweight centiles for all the major ethnic groups within a community should be produced [22].

It is important to note that our centile charts have been created without adjustment for factors which are known to have an impact on infant birthweight, such as maternal weight, height, parity, smoking status and socio-economic status $[27,28]$. This is also true for the currently used UK 1990 birthweight charts. Similarly, the usefulness of birthweight centiles to make inferences on fetal growth is inevitably limited by the missing data of the fetuses that remain in utero as infants born prematurely tend to be lighter than the fetuses of continuing pregnancies [29]. However, the main impact of the data we have presented is in relation to the otherwise normal term infants where the fetal weight of infants continuing in utero is less of an issue. Nonetheless, the charts from 32 to 36 weeks inclusive will be useful to midwives and neonatologists as postnatally charts of birthweights rather than estimated fetal weights are used as the basis of clinical decisionmaking.

The main aim of this work was to develop ethnic specific birthweight centile charts for South Asian infants and not to recreate WHO growth charts. Our charts will help to correctly allocate South Asian infants to a centile appropriate for their ethnic group. The important next step will be to assess whether the infants identified in this way are those with the appropriate clinical needs.

\section{Conclusion}

There is clear evidence that infants belonging to this UK-born South Asian ethnic group are lighter by 200$350 \mathrm{~g}$ across all gestational ages compared to their White British counterparts. Where there is enough data available, we believe it is important to create separate centile charts for ethnic groups where differences in birthweight exist.

This work is based on births in a single NHS trust and it is unknown if these centile charts are applicable to all populations of South Asians living in the UK. Therefore, it is important now to formally validate these centile charts in other UK-born South Asian populations. Further studies are also required to demonstrate that it is safe to treat as normal those South Asian infants who fall below the 10th centile on currently used birthweight charts, but are appropriately grown on our ethnic specific birthweight charts. Similarly, it must be assessed whether South Asian infants who are LGA on our charts face sim- 
ilar morbidities to White British infants who are LGA on the currently used birthweight charts.

If clinical studies do confirm that the ethnic specific charts correctly categorise babies in terms of their clinical needs, not only will care be improved but costs will also be reduced.

\section{Acknowledgements}

The authors would like to acknowledge Mikis Stasinopoulos for his help with the GAMLSS package and the NIHR for the provision of funding for S.E.S.

\section{References}

$\checkmark 1$ Wilcox A, Skjaercen R, Buekens P, et al: Birthweight and perinatal mortality. A comparison of the United States and Norway. JAMA 1995;273:709-711.

-2 Alexander G, Kogan M, Bader D, et al: US birthweight/gestational age-specific neonatal mortality: 1995-1997 rates for Whites, Hispanics, and Blacks. Pediatrics 2003;111: 61-66.

$\checkmark 3$ Barker D: Fetal origins of coronary heart disease. BMJ 1995;311:171-174.

-4 Baker J, Olsen L, Sørensen T: Weight at birth and all-cause mortality in adulthood. Epidemiology 2008;19:197-203.

$\checkmark 5$ Johansson S, Iliadou A, Bergvall N, et al: The association between low birthweight and type 2 diabetes: contribution of genetic factors. Epidemiology 2008;19:659-665.

6 Das S, Irigoyen M, Patterson M, et al: Neonatal outcomes of macrosomic births in diabetic and non-diabetic women. Arch Dis Child 2009;94:419-422.

7 Chiavaroli V, Giannini C, D’Adamo E, et al: Insulin resistance and oxidative stress in children born small and large for gestational age. Pediatrics 2009;124:695-702.

$>8$ David R, Collins J: Differing birthweight among infants of US-born Blacks, Africanborn Blacks, and US-born Whites. N Engl J Med 1997;337:1209-1214.

-9 Guendelman S, Buekens P, Blondel B, et al: Birth outcomes of immigrant women in the United States, France, and Belgium. Matern Child Health J 1999;3:177-187.
10 Migone A, Emanuel I, Mueller B, et al: Gestational duration and birthweight in White, Black and mixed-race babies. Paediatr Perinat Epidemiol 1991;5:378-391.

11 Harding S, Rosato M, Cruickshank J: Lack of change in birthweights of infants by generational status among Indian, Pakistani, Bangladeshi, Black Caribbean and Black African mothers in a British cohort study. Int J Epidemiol 2004;33:1279-1285.

-12 Doornbos J, Nordbeckb H, Van Enkc A, et al: Differential birthweights and the clinical relevance of birthweight standards in a multiethnic society. Int J Gynecol Obstet 1991;34: 319-324.

13 Chinn S, Cole T, Preece M, et al: Growth charts for ethnic populations in UK. Lancet 1996;347:839-840.

14 Cole T, Freeman J, Preece M: British 1990 growth reference centiles for weight, height, body mass index and head circumference fitted by maximum penalized likelihood. Statist Med 1998;17:407-429.

15 Freeman J, Cole T, Chinn S, et al: Cross-sectional stature and weight reference curves for the UK, 1990. Arch Dis Child 1995;73:17-24.

16 Cole T, Green P: Smoothing reference centile curves: the LMS method and penalized likelihood. Statist Med 1992;11:1305-1319.

17 Stasinopoulos D, Rigby R: Generalized additive models for location scale and shape (GAMLSS) in R. J Statist Softw 2007;23:146.

18 Development Core Team: R: A Language and Environment for Statistical Computing. Vienna, R Foundation for Statistical Computing, 2010.

19 WHO: WHO Child Growth Standards: Methods and Development. Geneva, WHO, 2006.
20 StataCorp: Stata Statistical Software, Release 11. College Station, StataCorp LP, 2009.

21 Rona R, Chinn S: National Study of Health and Growth: social and biological factors associated with height of children from ethnic groups living in England. Ann Hum Biol 1986; 13:453-471.

22 Ray J, Jiang D, Sgro M, et al: Thresholds for small for gestational age among newborns of East Asian ancestry. J Obstet Gynaecol Can 2009;31:322-330.

23 Singhal A, Lucas A: Early origins of cardiovascular disease: is there a unifying hypothesis? Lancet 2004;363:1642-1645.

24 Whincup P, Kaye S, Owen C, et al: Birthweight and risk of type 2 diabetes: a systematic review. JAMA 2008;300:2886-2897.

25 Essel J, Opai-Tetteh E: Macrosomia - maternal and fetal risk factors. S Afr Med J 1995; 85:43-46

26 Dornhorst A, Paterson C, Nicholls J, et al: High prevalence of gestational diabetes in women from ethnic minority groups. Diabet Med 1992;9:820-825.

27 Witter F, Luke B: The effect of maternal height on birth weight and birth length. Early Hum Dev 1991;25:181-186.

28 Okoro T, Njokanma F, Goswami K: The effects of sex, parity and maternal age on birth weights in a specialist hospital setting in $\mathrm{Ni}$ geria. J Obstet Gynaecol 2004;24:657-661.

29 Hutcheon J, Platt R: The missing data problem in birthweight percentiles and thresholds for 'small-for-gestational-age'. Am J Epidemiol 2008; 167:786-792. 